\title{
Early-Life Experience Reduces Excitation to Stress-Responsive Hypothalamic Neurons and Reprograms the Expression of Corticotropin-Releasing Hormone
}

\author{
Aniko Korosi, ${ }^{1}$ Marya Shanabrough, ${ }^{2}$ Shawn McClelland, ${ }^{1}$ Zhong-Wu Liu, ${ }^{3}$ Erzsebet Borok, ${ }^{2}$ Xiao-Bing Gao, ${ }^{3}$ \\ Tamas L. Horvath, ${ }^{2,3,4}$ and Tallie Z. Baram ${ }^{1}$ \\ ${ }^{1}$ Anatomy/Neurobiology and Pediatrics, University of California Irvine, Irvine, California 92697, and 2Program on Cell and Neurobiology of Energy \\ Metabolism, Section of Comparative Medicine, ${ }^{3}$ Department of Ob/Gyn and Reproductive Sciences, and ${ }^{4}$ Department of Neurobiology, Yale School of \\ Medicine, New Haven, Connecticut 06510-8016
}

Increased sensory input from maternal care attenuates neuroendocrine and behavioral responses to stress long term and results in a lifelong phenotype of resilience to depression and improved cognitive function. Whereas the mechanisms of this clinically important effect remain unclear, the early, persistent suppression of the expression of the stress neurohormone corticotropin-releasing hormone (CRH) in hypothalamic neurons has been implicated as a key aspect of this experience-induced neuroplasticity. Here, we tested whether the innervation of hypothalamic CRH neurons of rat pups that received augmented maternal care was altered in a manner that might promote the suppression of CRH expression and studied the cellular mechanisms underlying this suppression. We found that the number of excitatory synapses and the frequency of miniature excitatory synaptic currents onto CRH neurons were reduced in "care-augmented" rats compared with controls, as were the levels of the glutamate vesicular transporter vGlut2. In contrast, analogous parameters of inhibitory synapses were unchanged. Levels of the transcriptional repressor neuron-restrictive silencer factor (NRSF), which negatively regulates $\mathrm{Crh}$ gene transcription, were markedly elevated in care-augmented rats, and chromatin immunoprecipitation demonstrated that this repressor was bound to a cognate element (neuron-restrictive silencing element) on the Crh gene. Whereas the reduced excitatory innervation of $\mathrm{CRH}$-expressing neurons dissipated by adulthood, increased NRSF levels and repression of CRH expression persisted, suggesting that augmented early-life experience reprograms $\mathrm{Crh}$ gene expression via mechanisms involving transcriptional repression by NRSF.

\section{Introduction}

Early-life experience induces persistent neuroplasticity of the neuroendocrine stress system, with implications for emotional and cognitive function (Levine, 1967). This plasticity, characterized by reduced stress responses (Plotsky and Meaney, 1993; Avishai-Eliner et al., 2001a), increased resilience to depressivelike behavior (Meaney et al., 1991), and improved learning and memory (Liu et al., 2000; Fenoglio et al., 2005), can be induced by brief daily separation of rat pups from the dam during the first weeks of life, which promotes maternal-derived sensory input (Liu et al., 1997; Fenoglio et al., 2006).

At a molecular level, adult rats experiencing augmented maternal sensory input have altered basal expression of key neuronal genes involved in regulating neuroendocrine and behavioral stress responses (Joëls and Baram, 2009). These include reduced

\footnotetext{
Received Aug. 26, 2009; revised Nov. 17, 2009; accepted Nov. 18, 2009.

This work was supported by National Institutes of Health Grants NS28912, MH73136, DK-060711, DK-080000, and DK-070723. We thank Dr. Bart Pollux for statistical advice and Jessica Cope for assistance with the in situ hybridization.

Correspondence should be addressed to Tallie Z. Baram, Pediatrics and Anatomy/Neurobiology, University of California, Irvine, Z0T 4475, Irvine, CA 92697-4475. E-mail: tallie@uci.edu.

D0I:10.1523/JNEUROSCI.4214-09.2010

Copyright $\odot 2010$ the authors $\quad 0270-6474 / 10 / 300703-11 \$ 15.00 / 0$
}

expression of corticotropin-releasing hormone (CRH) in hypothalamic paraventricular nucleus neurons, attenuated hormonal stress response, and increased expression of glucocorticoid receptor in hippocampal neurons (Plotsky and Meaney, 1993; Liu et al., 1997; Fenoglio et al., 2005). Experience-induced reduction in CRH expression was apparent already by postnatal day 9 (P9), preceding both the diminished hormonal stress responses and the increased hippocampal glucocorticoid receptor (GR) expression (Avishai-Eliner et al., 2001a). These observations, together with the fact that the "experience-augmented" phenotype could be reproduced by reducing interactions of $\mathrm{CRH}$ with its receptor during development (Fenoglio et al., 2005), suggested that reduced CRH expression was an early, key element of the process leading from enhanced maternal sensory input to the enduring phenotype described above.

What is the nature of signals, derived from maternal sensory experience, that reaches $\mathrm{CRH}$ neurons? The $\mathrm{CRH}$ neuron is a component of a neuronal network activated by maternal care (Fenoglio et al., 2006). Therefore, it is reasonable to assume that augmented early-life experience alters excitatory and/or inhibitory synaptic input onto CRH neurons and that this alteration, in turn, triggers molecular machinery that enduringly reduces $\mathrm{CRH}$ expression. 
Synaptic innervation of individual (including hypothalamic) neurons has recently emerged as dynamic and modulated by experience (Verkuyl et al., 2004; Horvath, 2005). For CRH neurons, the majority of input is mediated by GABAergic and glutamatergic synapses (Boudaba et al., 1997; Miklos and Kovacs, 2002; Ziegler et al., 2005), via GABA $_{\mathrm{A}}$ (Cullinan, 2000) and glutamate receptors (Aubry et al., 1996; Kiss et al., 1996; Di et al., 2003). GABA and glutamate are transported into presynaptic vesicles by vesicular transporters, vGat (McIntire et al., 1997) and vGlut (Herzog et al., 2001), respectively, so that these transporters provide specific markers for inhibitory and excitatory afferent synaptic contacts onto CRH neurons. Here, we combined quantification of these markers, using Western blot, quantitative confocal and electron microscopy, and electrophysiology, to examine the effects of early-life experience on excitatory and inhibitory synapses abutting CRH neurons. We then examined the molecular machinery underlying the persistent suppression of $\mathrm{CRH}$ expression, testing whether augmented early-life experience increased expression of the repressor neuron-restrictive silencer factor (NRSF) (Mori et al., 1992; Palm et al., 1998), because of the presence of a functional binding site for this repressor within the Crh gene (Seth and Majzoub, 2001).

\section{Materials and Methods}

Animals. Thirty-two timed-pregnant Sprague Dawley rats were housed in an uncrowded, quiet animal facility room on a $12 \mathrm{~h}$ light/dark cycle and were provided with food and water ad libitum. Parturition was checked daily, and the day of birth was considered postnatal day P0. On $\mathrm{P} 2$, all pups were briefly gathered, and 10 pups were assigned at random to each dam. They experienced one of the following early-life rearing conditions: (1) brief separation from the dam (augmented care, or "augmented experience"), which took place daily from P2 to P8; or (2) undisturbed controls that remained in cages that were not touched between P2 and P8. Rats were either killed on P9, between 8:00 A.M. and 12:00 P.M., or maintained under standard animal facility rearing conditions, weaned on P21, and grown three to four per cage into adulthood. All experiments were approved by the University Animal Care Committee and conformed to National Institutes of Health (NIH) guidelines.

Augmentation of maternal care via brief daily separation and observation of maternal care. Cages were brought into the laboratory daily at 8:30 A.M. The dam and the pups were placed into separate bedded cages (pups were kept euthermic via a heating pad located underneath the cage). After $15 \mathrm{~min}$, pups were placed back into their home cage, followed by the dam, and returned to the vivarium. Undisturbed litters remained in the vivarium from P2 to P9. For all experimental groups, cage change did not occur during this time. After pups and the dam were returned to the vivarium, maternal behavior (including licking and grooming) was observed using a protocol based on the work of Liu et al. (1997) as used by Fenoglio et al. (2006). Maternal behavior was also determined in undisturbed litters. Each maternal observation session consisted of 10 epochs of 3 min each. Within each epoch, the duration of licking and grooming of pups was recorded during the first minutes. The total amount of time spent licking and grooming was scored per session, added for all the sessions, and multiplied by three to provide the total amount of maternal care during the 30 min session.

In situ hybridization for CRH mRNA. Rats were rapidly decapitated at P9 ( $n=5$ for control, $n=6$ for experience-augmented pups) and between P45 and P60 ( $n=4$ per group), and the brains were quickly dissected and frozen in dry ice. Brains were sectioned at $20 \mu \mathrm{m}$ using a cryostat, collected onto gelatin-coated slides, and stored at $-80^{\circ} \mathrm{C}$. In situ hybridization (ISH) histochemistry was conducted as described previously using deoxy-oligonucleotide probes (Avishai-Eliner et al., 2001b). The probe was labeled with ${ }^{35} \mathrm{~S}$ using routine terminal deoxynucleotide transferase methodology. Briefly, sections were brought to room temperature, air dried, and fixed in fresh $4 \%$ buffered paraformaldehyde (PFA) for $20 \mathrm{~min}$, followed by dehydration and rehydration through graded ethanols. Sections were exposed to $0.25 \%$ acetic anhydride and $0.1 \mathrm{M}$ triethanolamine, $\mathrm{pH}$ 8, for 8 min and dehydrated through graded ethanols. Prehybridization and hybridization steps were performed in a humidified chamber at $42^{\circ} \mathrm{C}$ in a solution of $50 \%$ formamide, $5 \times$ SET (750 mm NaCl, 150 mm Tris, 12.5 mm EDTA), $0.2 \%$ SDS, $5 \times$ Denhart's solution, $0.5 \mathrm{mg} / \mathrm{ml}$ salmon sperm DNA, $0.25 \mathrm{mg} / \mathrm{ml}$ yeast tRNA, 100 $\mathrm{mm}$ dithiothreitol, and $10 \%$ dextran sulfate. After a $1 \mathrm{~h}$ prehybridization, sections were hybridized overnight with $0.25 \times 10^{6} \mathrm{cpm}$ of labeled probe. After hybridization, sections underwent serial washes at $42^{\circ} \mathrm{C}$, most stringently at $0.3 \times$ SSC for $30 \mathrm{~min}$ at room temperature. Sections were then dehydrated through increasing ethanol concentrations, air dried, and apposed to film (Kodak BioMax MR Film; Eastman Kodak) for $5-10 \mathrm{~d}$.

The ISH signal was analyzed on scanned, digitized paraventricular nucleus of the hypothalamus (PVN) images of sections at coronal levels corresponding at $3.8-3.5 \mathrm{~mm}$ anterior to bregma. The Image Tool software program (University of Texas Health Science Center, San Antonio, TX) was used (Fenoglio et al., 2006) after determining the linear range of optical densities (ODs) using ${ }^{14} \mathrm{C}$ standards. Values were only used if they fell in the linear range and were corrected for background by subtracting the OD of signal over the thalamus. The OD from two optimal sections was averaged to generate an expression value for each PVN, which is expressed in nanocuries per gram. These values were then used to calculate group means \pm SEM.

Immunocytochemistry studies. At $\mathrm{P} 9$ or at $\mathrm{P} 45$, rats were anesthetized with sodium pentobarbital $(100 \mathrm{mg} / \mathrm{kg}$, i.p. $)$ and perfused through the ascending aorta with $0.9 \%$ saline solution, followed by freshly prepared, cold $4 \%$ PFA in $0.1 \mathrm{~m}$ sodium phosphate buffer (PB), pH 7.4, cryoprotected in 15 and $30 \%$ sucrose $/ \mathrm{PB}$ solution, and stored at $-80^{\circ} \mathrm{C}$. Brains were sectioned at $30 \mu \mathrm{m}$ using a cryostat, and sections were collected as four series with $90 \mu \mathrm{m}$ intervals between sections in tissue-culture wells containing $0.1 \mathrm{M}$ PB. Every fourth matched section was subjected to immunocytochemistry (ICC). For each experiment, sections of experience-augmented and control rat brains were processed concurrently in parallel wells.

For single-labeling CRH ICC, free-floating sections of experienceaugmented $(n=5)$ and control $(n=5)$ rats were subjected to standard avidin-biotin complex (ABC) methods (Fenoglio et al., 2006). Briefly, after several washes with $0.01 \mathrm{~m}$ PBS containing $0.3 \%$ Triton X-100, $\mathrm{pH}$ 7.4 (PBS-T), sections were treated for $30 \mathrm{~min}$ in $0.3 \% \mathrm{H}_{2} \mathrm{O}_{2}$ in PBS, followed by blockade of nonspecific sites with $1 \%$ bovine serum albumin (BSA) in PBS for $30 \mathrm{~min}$ and incubation for $48 \mathrm{~h}$ at $4^{\circ} \mathrm{C}$ with anti-CRH (1:40,000; gift from Dr. W. W. Vale, Salk Institute, La Jolla, CA) in PBS. After three 5 min washes in PBS-T, sections were incubated in biotinylated rabbit anti-goat IgG (1:200; Vector Laboratories) in PBS containing $1 \%$ BSA for $2 \mathrm{~h}$ at room temperature. After washing in PBS-T (three times for $5 \mathrm{~min}$ ), sections were incubated in $\mathrm{ABC}$ solution (1:100; Vector Laboratories) for $2 \mathrm{~h}$ at room temperature. Sections were then rinsed again in PBS (three times for $5 \mathrm{~min}$ ). The reaction product was visualized by incubating sections for $8-10 \mathrm{~min}$ in $0.04 \%$ 3,3-diaminobenzidine (DAB) containing $0.01 \% \mathrm{H}_{2} \mathrm{O}_{2}$.

All counts were performed without knowledge of experimental group (blindly). CRH-immunopositive cells were visualized using a Nikon E400 microscope and counted in anatomically matched sections using systematic sampling methods. Briefly, CRH-immunopositive cells were counted in four sections that were $90 \mu \mathrm{m}$ apart per animal. We obviated double counting by focusing throughout the $30 \mu \mathrm{m}$ section and including a cell only at the level at which it had a clear complete nuclear profile. Because the diameter of the CRH-positive cell nucleus was considerably smaller than the thickness of each cryostat section, each cell was counted once only. The PVN and central nucleus of the amygdala (ACe) were sampled at coronal levels $3.8-3.5 \mathrm{~mm}$ anterior to bregma, and the bed nucleus of the stria terminalis (BnST) was sampled at levels corresponding to $5.0-4.7 \mathrm{~mm}$ anterior to bregma. The intensity of CRH immunoreactivity was analyzed on photomicrographs taken through a digital camera (Spot Digital camera, RT color V3.0; Diagnostics Instruments) with a standardized light source and standardized exposure. Analyses were performed using ImageJ (version 1.41; NIH, Bethesda, MD). Densities are expressed in OD units after correcting for background by subtracting the density of the immunoreactive signal over the anterior 
commissure. Numbers of CRH-immunopositive neurons and CRH OD from four sections were averaged. The numbers of cells per section and OD per section were used to calculate group means \pm SEM.

For double-labeling ICC of CRH and vGlut2 (the predominant vGlut isoform in the hypothalamus) (Herzog et al., 2001), sections of experience-augmented and control rats ( $n=3$ per group) were washed three times for $10 \mathrm{~min}$ in $0.01 \mathrm{M}$ PBS and treated with $1 \%$ Triton X-100 in $0.01 \mathrm{M}$ PBS for $30 \mathrm{~min}$. Sections were placed in $2 \%$ normal goat serum and incubated for $48 \mathrm{~h}$ at $4^{\circ} \mathrm{C}$ in a mixture of rabbit anti-CRH serum $(1: 10,000)$ and guinea pig anti-VGlut2 serum (1:10,000; AB5907; Millipore). After three $10 \mathrm{~min}$ washes in $0.01 \mathrm{M}$ PBS, sections were incubated in a secondary antiserum mixture (1:400; goat anti-rabbit IgG 568 and goat anti-guinea pig IgG Alexa Fluor 488; Invitrogen).

The number of vGlut2 boutons contacting PVN-CRH neurons was assessed by confocal laser-scanning microscopic analysis ( $n=66$ cells for control, $n=76$ cells for experience-augmented rats). Images of the parvocellular division of the PVN (at coronal levels 3.8-3.5 mm anterior to bregma) were collected using an LSM510 confocal scanning system (Zeiss). Five $2-\mu \mathrm{m}$-thick optical sections were collected along the $z$-axis throughout the thickness of the whole neuron. Images were acquired with an excitation wavelength of $488 \mathrm{~nm}$ (green) and $543 \mathrm{~nm}$ (red) with a $40 \times$ oil objective using the minimum pinhole size. Images were imported as TIFF files at the resolution of $1024 \times 1024$ pixels. vGlut2 boutons contacting PVN-CRH neuron were counted through the complete $z$-axis in each optical section and averaged (vGlut2 boutons/optical section/CRH cell). A vGlut2 bouton was considered to be apposed to the CRH cell body only when there was no visible space between the CRH cell membrane and the bouton. In addition, cell size was measured in the central optical section for each CRH neuron using LSM Image browser software (version 4.2.0.121; Zeiss). Analyzed cells were selected based on the following criteria: (1) CRH immunopositive; (2) fully visible soma within the Z-stack; and (3) a clearly identifiable nucleus. After all of the quantitative analyses were completed, images used for illustration were optimized for brightness and contrast using Adobe Photoshop 7.0.

Western blot. Samples consisted of micropunched PVN (Palkovits, 1973 ) or dissected thalamus from an individual rat. Rats were rapidly decapitated at $\mathrm{P} 9$ ( $n=12$ per group) and at $\mathrm{P} 45$ ( $n=5$ per group), and the brains were quickly dissected and frozen on powdered dry ice. The PVN was punched out (21 gauge needle) from consecutive $150-\mu \mathrm{m}$ thick cryostat sections. Tissue was homogenized in $1.5 \mathrm{ml}$ Eppendorf tubes in ice-cold $0.32 \mathrm{M}$ sucrose and $0.1 \mathrm{~m}$ Tris- $\mathrm{HCl}, \mathrm{pH} 7.4$, containing a protease inhibitor mixture (Complete; Roche; diluted according to the manufacturer's instructions). Protein concentration was determined (Bio-Rad), and equal amounts of protein were diluted in Laemmli buffer, separated by SDS-PAGE, and visualized using the enhanced chemiluminescence (ECL)-Plus kit (GE Healthcare) as described previously (Brewster et al., 2005). Briefly, $2 \mu \mathrm{g}$ of protein extracts were separated on a $10 \%$ SDS-PAGE and transferred to Hybond-P polyvinyl difluoride membranes (GE Healthcare). Membranes were blocked with $10 \%$ nonfat milk in $1 \times$ PBS overnight at $4^{\circ} \mathrm{C}$ and probed with guinea pig anti-vGlut2 (1:800,000; AB5907; Millipore), rabbit anti-vGat (1:150,000; generous gift from Dr. R. Edwards, University of California San Francisco, San Francisco, CA), or rabbit anti-NRSF (1:20,000; H-290-sc25398; Santa Cruz Biotechnology) in each case combined with rabbit anti-actin (1: 60,000; Sigma). After washes in PBS-T (three times for $5 \mathrm{~min}$ ), membranes were incubated with secondary antibodies made in donkey, conjugated to horseradish peroxidase $(1: 10,000)$ in $5 \%$ nonfat milk in PBS for $1 \mathrm{~h}$ at room temperature. Membranes were washed in PBS-T (three times for $5 \mathrm{~min}$ ) and incubated with ECL-Plus. Immunoreactive bands were visualized by apposing membranes to Hyperfilm ECL (GE Healthcare). PVN and thalamic extracts of individual rats of different groups were run concurrently on the same gel. Specificity of signal was examined by excluding the primary antibodies in the presence of the secondary antibodies. These treatments resulted in no immunoreactive vGlut2, vGat, or NRSF bands.

Western blot data acquisition and analysis were accomplished by measuring the OD of immunoreactive bands from the ECL films using ImageTool. Several durations of exposure were performed to ascertain that ODs were in a linear range. The OD of vGlut2, vGat, and NRSF bands was normalized to $\beta$-actin of the same sample. Individual ODs were normalized to the mean value of the control OD and used to generate mean values per group \pm SEM.

Electron microscopic immunostaining. P9 rats were anesthetized with sodium pentobarbital $(100 \mathrm{mg} / \mathrm{kg}$, i.p.) and perfused through the ascending aorta with $0.9 \%$ saline solution, followed by freshly prepared, cold $4 \%$ PFA; $15 \%$ picric acid; and $0.08 \%$ glutaraldehyde in $0.1 \mathrm{M} \mathrm{PB}, \mathrm{pH}$ 7.4. Brains were removed and postfixed in $4 \%$ PFA overnight and stored in $0.1 \mathrm{M} \mathrm{PB}$. Brains were sectioned at $30 \mu \mathrm{m}$ using a Vibratome (Lancer), and sections were collected in multiwell plates containing $0.1 \mathrm{M}$ PB. For CRH ICC, free-floating sections of experience-augmented $(n=5)$ and control $(n=5)$ rats were processed according to standard ABC methods with minor adaptations for the electron microscopic staining. Specifically, sections were treated for $30 \mathrm{~min}$ in $0.3 \% \mathrm{H}_{2} \mathrm{O}_{2}$ in PBS. Sections were incubated for $1 \mathrm{~h}$ in freezing solution $(0.1 \mathrm{M} \mathrm{PB}, 25 \%$ sucrose, and $10 \%$ glycerol) followed by freeze/thaw in liquid nitrogen repeated three times. Then sections were washed several times with $0.01 \mathrm{M}$ PBS, followed by incubation in $1 \%$ BSA in PBS for 30 min to block nonspecific staining. After a 10 min rinse in PBS, sections were incubated for $48 \mathrm{~h}$ at $4^{\circ} \mathrm{C}$ with anti-CRH $(1: 40,000)$ in PBS containing $1 \%$ BSA and washed three times in PBS-T for 5 min each. Subsequently, sections were incubated in biotinylated rabbit anti-goat IgG (1:200; Vector Laboratories) in PBS for $2 \mathrm{~h}$ at room temperature. After washing in PBS (three times for $5 \mathrm{~min}$ ), sections were incubated in $\mathrm{ABC}$ solution (1:100; Vector Laboratories) for $2 \mathrm{~h}$ at room temperature. Sections were then rinsed again in PBS (three times for $5 \mathrm{~min}$ ). The reaction product was visualized by incubating sections for $8-10 \mathrm{~min}$ in $0.04 \% \mathrm{DAB}$ containing $0.01 \% \mathrm{H}_{2} \mathrm{O}_{2}$. Sections were then osmicated $\left(1 \% \mathrm{OsO}_{4}\right.$ in $\left.\mathrm{PB}\right)$ for $30 \mathrm{~min}$, dehydrated through increasing ethanol concentrations (using 1\% uranyl acetate in 70\% ethanol for $30 \mathrm{~min}$ ), and flat embedded in Durcupan between liquid releasecoated slides and coverslips (Electron Microscopy Sciences) followed by capsule embedding. Blocks were trimmed, and ribbons of serial ultrathin sections were cut (Leica Ultracut E), collected on Formvar-coated single slot grids, and examined under an FEI Biotwin electron microscope.

Semiquantitative analysis. The quantitative and qualitative analysis of synapse number was performed in a blinded manner. To obtain a complementary measure of an axosomatic synaptic number, unbiased for possible changes in synaptic size, the dissector technique was used. On consecutive 90-nm-thick sections, we determined the average projected height of the synapses and used about $30 \%$ of this value as the distance between the dissectors. On the basis of this calculation, the number of axosomatic synapses was counted in two consecutive serial sections about $270 \mathrm{~nm}$ apart (termed "reference" and "look-up" sections) of 10 $\mathrm{CRH}$-immunolabeled perikarya profiles in each animal. Synapse characterization was performed at a magnification of 20,000. Symmetric and asymmetric synapses were counted on all selected neurons only if the presynaptic and/or postsynaptic membrane specializations were seen and synaptic vesicles were present in the presynaptic bouton. Synapses with neither clearly symmetric nor asymmetric membrane specializations were excluded from the assessment. The plasma membranes of selected cells were outlined on photomicrographs, and their length was measured with the help of a cartographic wheel. Plasma membrane length values measured in the individual animals were added, and the total length was corrected to the magnification applied. Synaptic densities were evaluated according to the formula $N V=Q-/ V_{\text {dis }}$, where $N V$ is the number per volume, $Q-$ is the number of synapses present in the reference section that disappeared in the look-up section, and $V_{d i s}$ is the dissector volume (volume of reference), the area of the perikarya profile multiplied by the distance between the upper faces of the reference and look-up sections (i.e., the data are expressed as numbers of synaptic contacts per unit volume of perikaryon). Section thickness was determined using the Small's minimal fold method. The synaptic counts were expressed as numbers of synapses on a $100 \mu \mathrm{m}$ membrane length unit.

Electrophysiology. Whole-cell recordings were made from presumed $\mathrm{CRH}$ neurons from the parvocellular paraventricular hypothalamic nucleus. Rats were rapidly decapitated at P9 ( $n=8$ rats per group), and at P30 ( $n=3$ rats per group), brains were quickly dissected and $300 \mu \mathrm{m}$ hypothalamic slices were cut using a vibratome. Hypothalamic slices were maintained at $33^{\circ} \mathrm{C}$ and perfused with artificial CSF (ACSF). The 
bath solution (ACSF) consisted of (in mM) $124 \mathrm{NaCl}, 3 \mathrm{KCl}, 2 \mathrm{CaCl}_{2}, 2$ $\mathrm{MgCl}_{2}, 1.23 \mathrm{NaH}_{2} \mathrm{PO}_{4}, 26 \mathrm{NaHCO}_{3}$, and 10 glucose, $\mathrm{pH} 7.4$, with $\mathrm{NaOH}$ and was continuously bubbled with $5 \% \mathrm{CO}_{2}$ and $95 \% \mathrm{O}_{2}$. The patch pipettes were made of borosilicate glass (World Precision Instruments) with a Sutter micropipette puller (PP-97). The tip resistance of the recording pipettes was $4-6 \mathrm{M} \Omega$ after filling with a pipette solution containing $145 \mathrm{~mm} \mathrm{KMeSO}_{4}, 1 \mathrm{~mm} \mathrm{MgCl}_{2}, 10$ mм HEPES, 1.1 mм EGTA, 2 mM Mg-ATP, and $0.5 \mathrm{~mm} \mathrm{Na}_{2}$-GTP, pH 7.3, with $\mathrm{KOH}$ and $0.1 \%$ Lucifer yellow (LY). After a gigaohm seal and a whole-cell access were achieved, the series resistance was between 20 and $40 \mathrm{M} \Omega$ and partially compensated by the amplifier. Both input resistance and series resistance were monitored throughout the experiments. Miniature EPSCs (mEPSCs) and miniature IPSCs (mIPSCs) were recorded under voltage clamp in the presence of tetrodotoxin (TTX) and bicuculline with a pipette solution containing $\mathrm{KMeSO}_{4}$ (for mEPSCs) or TTX and CNQX plus AP-5 with a pipette solution containing $\mathrm{KCl}$ (for mIPSCs) with a multiclamp 700A amplifier (Molecular Devices). The use of $\mathrm{KCl}$ significantly increases the conductance of $\mathrm{GABA}_{\mathrm{A}}$ receptors and makes recording mIPSCs easier. PVN cells were held at $-60 \mathrm{mV}$. Detection of mEPSC and mIPSC events were performed off-line with the software Axograph 4.9 (Molecular Devices). The frequency and amplitude of mEPSCs (or mIPSCs) were generated after detection of mEPSC events, as described previously (Gao and van den Pol, 2001). Putative CRH neurosecretory parvocellular PVN neurons were identified on the basis of their visualized position within the PVN and based on the shape of the neuron.

Immunocytochemical identification of CRH neurons. After recording with electrodes containing LY in the pipette solution, slices were postfixed overnight in $4 \%$ PFA at $4^{\circ} \mathrm{C}$ overnight, washed in $0.1 \mathrm{M} \mathrm{PB}$, embedded in agar, and sliced with a vibratome to $50-\mu \mathrm{m}$-thick sections. After washes in PBS-T, sections were incubated with rabbit anti-CRH $(1: 10,000)$ in $1 \%$ BSA in PBS-T for $48 \mathrm{~h}$ at $4^{\circ} \mathrm{C}$. After three 5 min washes in PBS-T, goat anti-rabbit antibody (Alexa Fluor $568 ; 1: 400$ ) in 1\% BSA in PBS-T was applied for $3 \mathrm{~h}$ to label CRH neurons. Sections were then sealed on glass slides with Vectashield to avoid bleaching and examined with a fluorescent microscope (Zeiss Axiophot microscope). The overlap of LY images with Alexa Fluor 568 staining was taken as identification of CRH neurons; however, leakage of cell contents including the LY in the slices impeded positive identification of the recorded neurons. Therefore, we considered for analysis only recorded neurons residing in the CRH-rich, dorsomedial parvocellular field of the PVN.

Chromatin immunoprecipitation. Chromatin immunoprecipitation (ChIP) assay was based on a fast ChIP protocol (Nelson et al., 2006). Brains were dissected from P12 rats, and hippocampi were isolated, frozen in tubes on dry ice, and stored at $-80^{\circ} \mathrm{C}$ until use. All ChIP buffer solutions contained protease inhibitor complex (Roche). Cross-linking was achieved by adding $1 \mathrm{ml}$ of $1 \%$ formaldehyde in PBS, dicing the tissue with scissors, and incubating at room temperature for $20 \mathrm{~min}$. Samples were spun $5 \mathrm{~min}$ at $800 \times g$ at $4^{\circ} \mathrm{C}$, and the supernatant was discarded. Pellets were washed twice with $1 \mathrm{ml}$ of $0.125 \mathrm{M}$ glycine in PBS and spun 5 $\min$ at $800 \times g$, and the supernatant was discarded. Next, tissue was homogenized in $1 \mathrm{ml}$ of hypotonic buffer $(10 \mathrm{~mm} \mathrm{KCl,} 10 \mathrm{~mm}$ Tris, $\mathrm{pH} 8$, and $1.5 \mathrm{~mm} \mathrm{MgCl}_{2}$ ) using a Dounce homogenizer with an A pestle. Samples were then incubated on ice for $15 \mathrm{~min}$, allowing the cells to swell, followed by the addition of $100 \mu \mathrm{l}$ of $10 \% \mathrm{NP}-40$ and spinning of samples $1 \mathrm{~min}$ at $16,000 \times \mathrm{g}$. The supernatant was discarded, and $360 \mu \mathrm{l}$ of radioimmunoprecipitation assay (RIPA) lysis buffer (50 mM Tris, 150 mм NaCl, 1\% NP-40, 0.1\% SDS, 5 mm EDTA, and 1 mм EGTA) was added to the remaining nuclear pellet. Samples were then sonicated for $10 \mathrm{~min}$ on a high setting ( $30 \mathrm{~s}$ on/30 s off) using a Bioruptor sonicator (Diagenode). Samples were then spun $5 \mathrm{~min}$ at $16,000 \times g$, and the top $350 \mu \mathrm{l}$ of the supernatant was added to $100 \mu \mathrm{l}$ of $50 \%$ protein $\mathrm{G}$-agarose bead slurry blocked with salmon sperm DNA (Millipore) and $1 \mathrm{ml}$ of RIPA buffer. Samples were incubated on a rotator at $4^{\circ} \mathrm{C}$ for $1 \mathrm{~h}$, spun at $3300 \times g$ for $1 \mathrm{~min}$, and transferred to new tubes as ChIP input samples. From ChIP input tubes, $425 \mu \mathrm{l}$ samples were aliquoted to new tubes for incubation with $2.5 \mu \mathrm{g}$ of NRSF antibodies (H290; Santa Cruz Biotechnology) or IgG. Samples were incubated on a rotator at $4^{\circ} \mathrm{C}$ overnight and spun at $16,000 \times g$ for $10 \mathrm{~min}$, and the top $360 \mu \mathrm{l}$ of the supernatant was transferred to a tube containing $30 \mu \mathrm{l}$ of $50 \%$ protein G-agarose

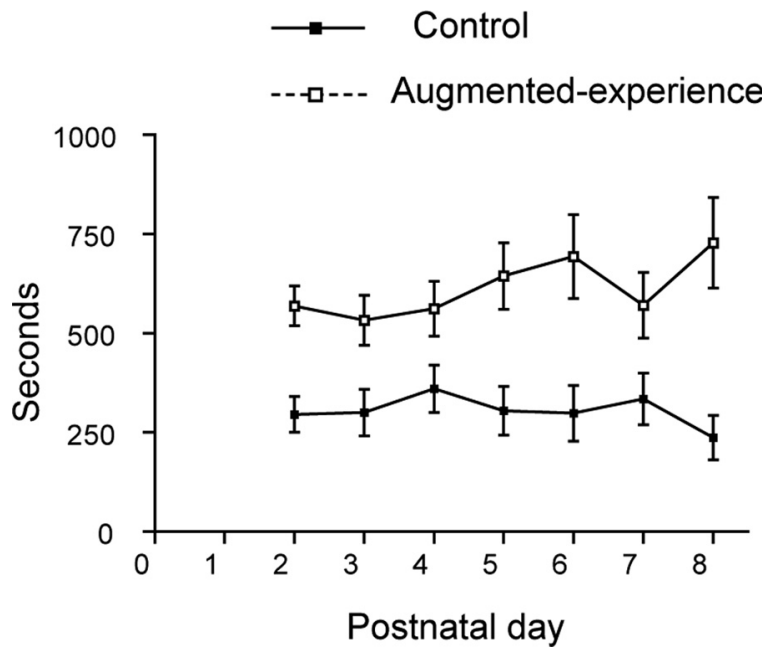

Figure 1. Sensory stimulation of pups by the dam is enhanced daily after brief separation of pups from their mother. Maternal stimulation of the pups, specifically licking and grooming, was observed and quantified daily from $\mathrm{P} 2$ to $\mathrm{P} 8$ during the $30 \mathrm{~min}$ after the return of separated pups and dams to home cages. The duration of these sensory stimulations of the pups was twofold higher in litters that were separated compared with control dams on each day $(n=16$ dams per group; repeated-measures ANOVA; $\left.F_{(1,31)}=39.94 ; p<0.0001\right)$.

beads. Samples were incubated on the rotator at $4^{\circ} \mathrm{C}$ for $1 \mathrm{~h}$ and spun at $3300 \times g$ for $1 \mathrm{~min}$. The supernatant was discarded, and the beads were washed five times by adding $1 \mathrm{ml}$ of RIPA buffer, incubating on the rotator at $4^{\circ} \mathrm{C}$ for $5 \mathrm{~min}$, spinning at $3300 \times \mathrm{g}$, and aspirating the supernatant. A total of $65 \mu \mathrm{l}$ of $20 \%$ Chelex (Bio-Rad) in water was added to 20 $\mu \mathrm{l}$ aliquots of the original ChIP input samples and to each pellet. The tubes were briefly mixed with a Vortex mixer and incubated in boiling water for $10 \mathrm{~min}$. The samples were allowed to cool and were spun at $16,000 \times g$ for $2 \mathrm{~min}$. The top $35 \mu \mathrm{l}$ of supernatant containing immunoprecipitated or input DNA was transferred to new tubes for analysis.

PCR on recovered DNA was performed using primers directed at the Crh gene (forward, AGTTTGGGGAAGACTTAGGAAGAG; reverse, CTATCCGACAGACACAGACAAGAC) or the $\beta$ actin gene (forward, GACTACCTCATGAAGATCCTGACC; reverse, GAGACTACAACTTACCCAGGAAGG). Gotaq green (Promega) polymerase mix was used with $10 \mu \mathrm{M}$ of each primer and 1-4 $\mu \mathrm{l}$ of DNA template per $20 \mu \mathrm{l}$ reaction. ChIP input DNA samples were used to adjust the amount of DNA used in each PCR to equivalent levels. After 30 cycles of PCR, products were run through gel electrophoresis along with samples of a quantitative DNA ladder (Bioline Hyperladder I). Ethidium bromide and UV light was used to visualize the DNA bands, and images were captured. Image analysis was performed on blinded samples using ImageJ software (NIH) to produce a standard curve from the quantitative DNA ladder. Band intensities for the PCR products were quantified using the standard curve.

Statistical considerations and analyses. All analyses were conducted without the knowledge of treatment. The significance of differences between groups was set at 0.05 . Differences in the maternal behavior of control and experimental dams were analyzed using repeated-measures ANOVA, in which treatment and time were included as fixed effects and dam was included as a repeated (subject) effect, using SAS version 9.2 (SAS Institute). To correct for potential litter effect, the significance of differences among groups were examined using a mixed-model ANOVA with treatment as a fixed effect and the dam as a random effect, using SAS.

\section{Results}

Brief daily separation of the pups from their mother increases sensory stimulation of pups by the dam

Brief (15 min) separation of pups from their mother ("handling") has been shown to enhance maternal nurturing behaviors, such as licking and grooming, toward the pups (Brown et al., 1977; Liu et al., 1997; Fenoglio et al., 2006). In addition, our 
A P9

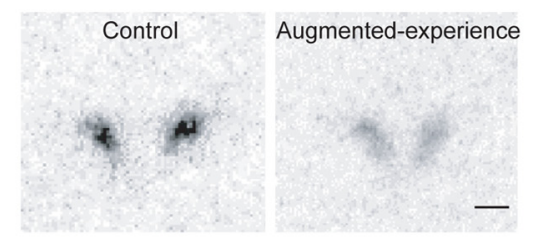

B Control Augmented-experience

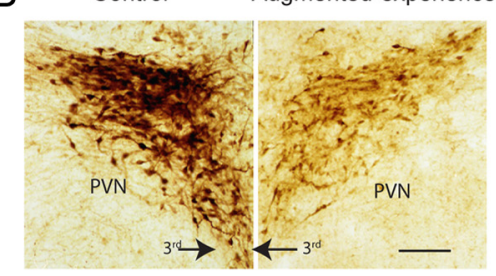

C Control

Augmented-experience
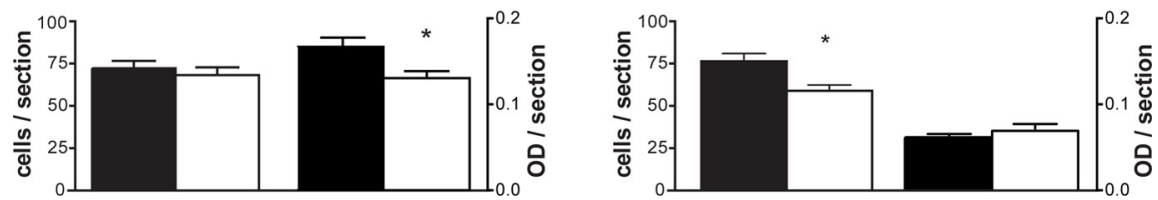

Figure 2. Augmented early-life experience leads to early onset and persistent reduction in CRH expression in parvocellular PVN at both mRNA and protein levels. $A$, Representative bright-field photomicrographs of coronal sections at the level of the PVN from control and experience-augmented rats. The sections were subjected to ISH for CRH mRNA. CRH mRNA expression was reduced by $52 \%$ in P9 experience-augmented rats compared with undisturbed controls. $\boldsymbol{B}$, Bright-field photomicrographs, taken under similar viewing parameters, showing CRH immunohistochemistry in PVN of control and experience-augmented rats. C, Quantitative analysis of the numbers of CRH-ir neurons and intensity of the immunoreactivity. The changes observed for mRNA expression were translated to protein levels as apparent from the $\sim 20 \%$ reduction in the intensity of CRH expression in experience-augmented rats. $D$, Representative autoradiographs after CRH mRNA ISH of CRH mRNA signal in adult control and experience-augmented rat PVN. CRH expression in experience-augmented adult rats was $50 \%$ lower compared with controls, indicating that repressed CRH expression, found on P9, was long-lasting. $E$, $F$, Brightfield photomicrographs and quantitative analysis of CRH immunohistochemistry in adult PVN. The enduring suppression of CRH expression observed at the mRNA level was translated to the protein level as evident from the $\sim 21 \%$ reduction in CRH-ir cells in the experienceaugmented rats. 3rd, Third ventricle. Scale bars: $A, D, 500 \mu \mathrm{m} ; \boldsymbol{B}, E, 200 \mu \mathrm{m}$. Data are represented as mean \pm SEM. ${ }^{*} p<0.05$.
A

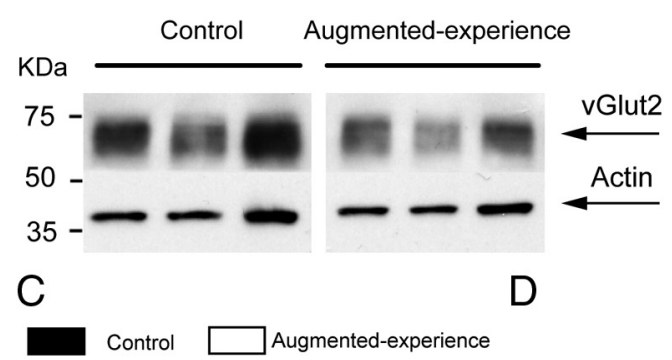

B

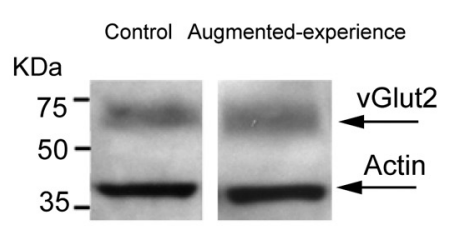

PVN
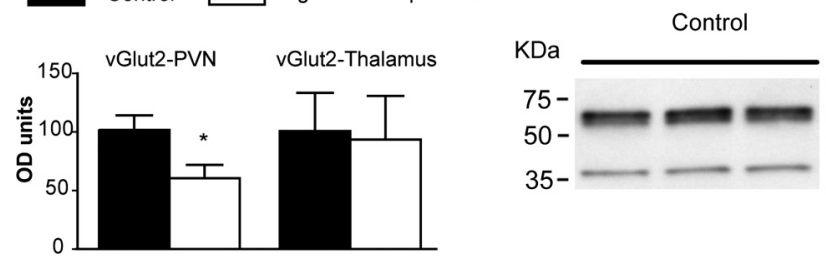

Augmented-experience

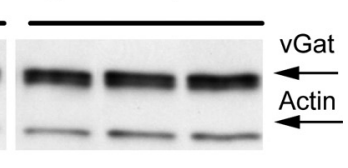

Figure 3. Levels of the marker for excitatory synapses vGlut2 are reduced in PVN from immature rats with augmented early-life experience compared with controls.A, C, Representative Western blots and quantitative analysis of $v$ Glut2 protein expression in the PVN of P9 controls and rats with augmented early-life experience. vGlut2 levels were reduced by $40 \%$ in augmented-experience rats compared with controls. $B, C$, Western blots and quantification of $v$ Glut2 in thalamic tissue of $P 9$ control and augmented early-life experience cohorts. No differences in thalamic vGlut2 levels were seen, indicating that the reduction in vGlut2 levels was specific to the PVN. $\boldsymbol{D}$, Western blot vGat levels in the PVN of P9 control rats compared with cohorts with augmented early-life experience. vGat levels in the PVN were not affected by this early-life experience. All groups were run concurrently on the same gels, and the $0 \mathrm{D}$ of vGlut2- and vGat-ir bands was normalized to that of actin for each lane. Data are represented as mean \pm SEM. ${ }^{*} p<0.05$. previous work found that bursts or a vigorous bout of sensory input to the pups was generated during the 30 min after the return of the pups to the dam. These findings were confirmed in the current experiments: the return of the pups to the home cage elicited a barrage of maternally derived sensory stimulation. Specifically, maternal licking and grooming was increased twofold during the first $30 \mathrm{~min}$ after the pups' return (controls, $304.2 \pm$ $14.4 \mathrm{~s}$ vs separated dams, $614.4 \pm 28.2 \mathrm{~s}$; $\left.F_{(1,31)}=39.94 ; p<0.0001\right)$ These bursts of sensory stimulation of the pups occurred daily throughout the week of the experiment (Fig. 1).

\section{CRH levels in the hypothalamic} $\mathrm{PVN}$ are reduced by augmented early-life experience

Hypothalamic parvocellular CRH expression at the mRNA and protein levels were examined on $\mathrm{P} 9$ in rats experiencing the augmented maternal care from P2 to P8, compared with controls that were raised without disturbance. CRH mRNA levels in the PVN of separated rats (experience augmented) were significantly lower than those of control pups $(61 \pm 6.3 \%$; $p<$ 0.05 ) (Fig. 2A), and this was observed already by $\mathrm{P} 9$, consistent with previous findings (Avishai-Eliner et al., 2001a; Fenoglio et al., 2006). These changes in mRNA expression were translated into changes in protein expression. As shown in Figure 2, $B$ and $C$, the intensity of CRH immunoreactivity over the PVN was reduced in the experience-augmented group (experience augmented, $0.13 \pm$ 0.04 OD units/section vs control animals, $0.16 \pm 0.05$ OD units/section; $p<0.05$ ), whereas the total number of CRH-expressing neurons was unchanged (control, $71 \pm 5$ cells/section; experience-augmented rats, $68 \pm 5$ cells/section). The effects of augmented early-life experience were specific to the $\mathrm{CRH}$-expressing neuronal population in the hypothalamic PVN: neither the overall OD nor the total number of CRH-immunopositive cells was altered in the ACe or the BnST. Thus, $\mathrm{CRH}$ immunoreactivity in ACe in P9 experience-augmented and control rats averaged $0.06 \pm 0.02$ and $0.06 \pm 0.02 \mathrm{OD}$ units/section, respectively, and the numbers of neurons expressing CRH in ACe averaged $12 \pm 1$ and $13 \pm 1$ cells/section, respectively. The BnST of control rats had an average of $0.05 \pm 0.02 \mathrm{OD}$ units/section and $48 \pm 2 \mathrm{CRH}$-expressing neurons/section compared with $0.05 \pm 0.02 \mathrm{OD}$ units/section and $40.0 \pm 5$ cells/section in BnST from experience-augmented rats. 
The longevity of the altered CRH expression was examined in rats experiencing augmented maternal care from P2 to P8 and killed as young adults (at P45-P60). At the mRNA level, PVN CRH expression remained lower in experience-augmented rats (50 $\pm 4 \%$ of control values; $p<0.001$ ) (Fig. $2 D)$, consistent with our previous findings (Avishai-Eliner et al., 2001a; Fenoglio et al., 2005). This reduction was evident also at the protein level (Fig. 2E,F). The number of $\mathrm{CRH}$-expressing neurons was lower $(58 \pm 4$ neurons/section) in adult experience-augmented rats compared with the control cohort (75 \pm 4 neurons/section; $p<0.05$ ), whereas the intensity of CRH immunoreactivity was not altered (control, $0.06 \pm 0.02$ OD units/section vs experience-augmented rats, $0.07 \pm 0.02 \mathrm{OD}$ units/section). Similar to $\mathrm{P} 9$, this reduction was specific to the PVN, because no differences in the number of CRH-expressing neurons or intensity of the immunoreactive signal were detected in the ACe (control, $0.10 \pm 0.05$ OD units/ section and $47 \pm 10$ cells/section; experience-augmented rats, $0.12 \pm 0.05 \mathrm{OD}$ units/ section and $44 \pm 4$ cells/section) or in the BnST (control, $0.13 \pm 0.05$ OD units/section and $17 \pm 6$ cells/section; experienceaugmented rats, $0.13 \pm 0.07$ OD units/ section and $12 \pm 2$ cells/section). Interestingly, the numbers of $\mathrm{CRH}$ cells in the ACe and BnST differed in both groups between $\mathrm{P} 9$ and $\mathrm{P} 45$, with inverse trends in cell numbers with age in the two structures. We can only speculate that this might be a result of developmental changes.

\section{Repressed CRH expression in PVN} neurons of experience-augmented rats is associated with reduction in excitatory synaptic input

The reduction in CRH expression in PVN of experience-augmented rats starts early (P9), endures for life, and is associated with lifelong reduction in hormone release in response to stress, potentially indicating altered sensitivity of the $\mathrm{CRH}$ neuron to excitation by stress. Therefore, we tested the possibility that augmented early-life experience leads to a reduced excitatory drive (or increased inhibition) onto CRH-expressing neurons.

We first examined whether the levels of the vesicular transporters of glutamate (vGlut2) and GABA (vGat), which are markers of presynaptic elements of glutamatergic and GABAergic synapses, respectively, were influenced by augmented maternal care. In punched PVN tissue, vGlut2 was detected as a single major band ( $\sim 60 \mathrm{kDa})$ (Fremeau et al., 2004). Protein levels of vGlut2 (normalized per actin and per controls) were significantly lower in experience-augmented compared with control rats: $60.5 \pm$ 11.4 versus $101.7 \pm 12.5$ OD units, respectively $(p<0.01)$ (Fig. $3 A, C)$. The changes in vGlut 2 were selective to the PVN and were not observed in the thalamus (controls, $100.0 \pm 32.4$ vs experience

C Control
B

Augmented-experience
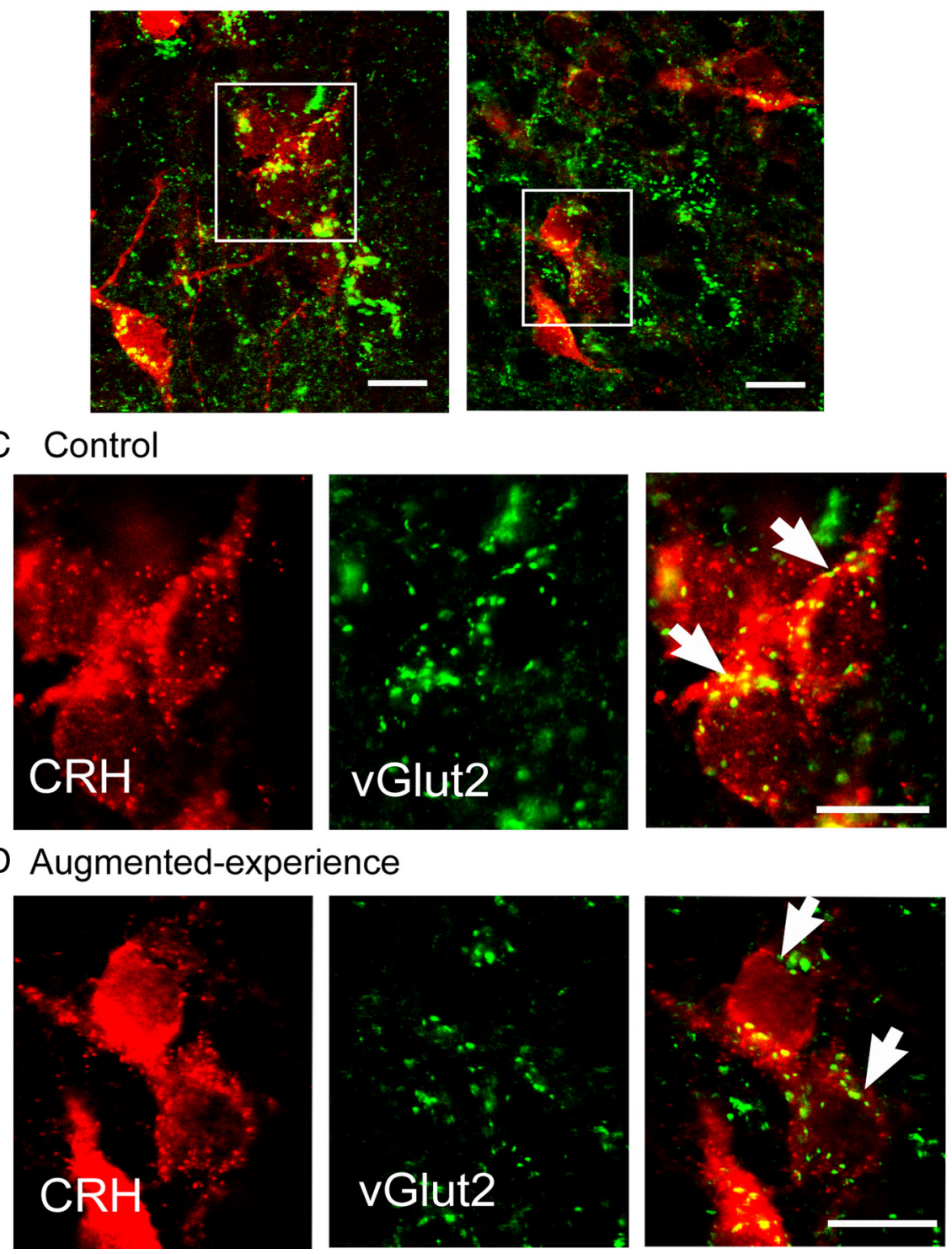

Figure 4. Fewer excitatory (vGlut2-positive) boutons contact CRH-ir neurons in parvocellular PVN of immature rats with augmented maternal experience compared with the controls. $\boldsymbol{A}, \boldsymbol{B}$, Merged confocal microscope images of sections at the level of the PVN double labeled for vGlut2 (green) and CRH (red) in control and augmented early-life experience P9 rats. vGlut2-ir boutons were of CRH-ir neurons (arrow) was reduced by $36 \%$ in augmented early-life experience rats compared with controls, as shown in the high-magnification confocal images. C, D, CRH immunostaining (left), vGlut2-immunopositive boutons (middle), and merged image (right). Cell sizes, assessed by measurement of the circumference of the soma of PVN CRH-expressing cells, were not different between experience-augmented and control rats. Scale bars, $10 \mu \mathrm{m}$.

augmented, $92.9 \pm 36.9$ ) (Fig. $3 B, C$ ). In contrast to vGlut2, protein levels of vGat were unaffected by early-life experience ( $49.1 \pm 6.6 \mathrm{vs}$ $59.1 \pm 8.7 \mathrm{OD}$ units in experience-augmented and control groups) (Fig. 3D).

The numbers of vGlut 2 boutons contacting CRH-

immunoreactive (ir) neurons in the parvocellular PVN are lower in rats experiencing augmented maternal care early in life compared with controls

To examine whether the reduction in vGlut2 protein levels in experience-augmented rat PVN represented a reduced number of glutamatergic, excitatory synapses onto $\mathrm{CRH}$ neurons, we 
A

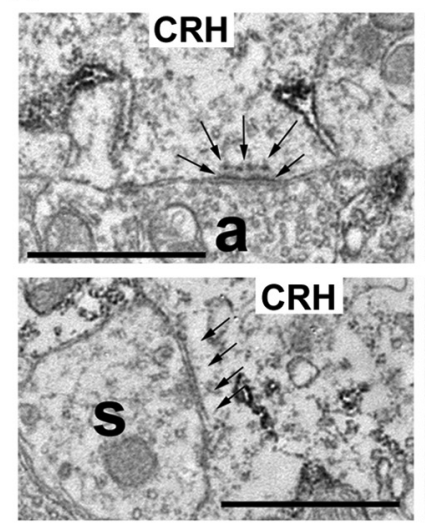

B

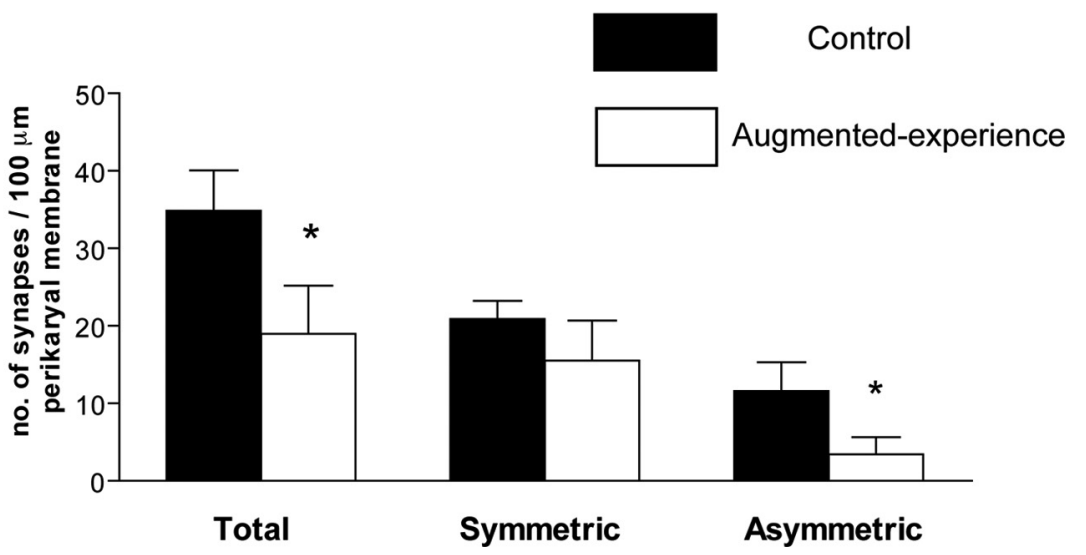

Figure 5. Augmented early-life experience induces a lower number of asymmetrical putative excitatory synapses onto CRH neurons. $\boldsymbol{A}$, Left, High-magnification electron micrographs showing asymmetric (a; excitatory) and symmetric ( $s$; inhibitory) synaptic contacts between parvocellular (RH-immunopositive soma and unidentified axon terminals (arrows). Right, Examples of synaptic contacts between CRH neurons and unidentified axon terminals (asterisks) of experience-augmented and control P9 rats. $\boldsymbol{B}$, Quantification of the total asymmetric and symmetric synapse density revealing $50 \%$ reduction in the total number of synapses attributable to a $70 \%$ reduction in number of asymmetric synapses onto CRH neurons of augmented early-life experience rats. Scale bars, $1 \mu \mathrm{m}$. Data are represented as mean \pm SEM. ${ }^{*} p<0.05$.

identified excitatory glutamatergic boutons on CRH neurons using double immunolabeling for vGlut 2 and $\mathrm{CRH}$. In virtual confocal sections $(2 \mu \mathrm{m})$, vGlut2-ir axon varicosities were frequently juxtaposed onto somata and proximal dendrites of $\mathrm{CRH}$-ir neurons. The CRH-expressing neurons were located in the medial parvocellular subdivision of the PVN (Sawchenko and Swanson, 1985), and their total numbers per section did not differ among the two experimental groups (see above). The numbers of vGlut2 boutons on individual CRH-ir cells were lower in experience-augmented rats (5.4 \pm 0.9 vGlut 2 boutons/optical section/cell) compared with controls $(8.4 \pm 0.9 ; p<0.05)$ (Fig. 4). The size of CRH neurons, as assessed by measuring cell surface was not affected by the early-life experience (perimeter: controls, $32.87 \pm 0.48 \mu \mathrm{m}, n=37$ cells from three rats; experience-augmented pups, $33.36 \pm 0.51 \mu \mathrm{m}, n=41$ cells from three rats; $p>0.3$ ).

The number of asymmetric synapses on PVN-CRHimmunolabeled cells is reduced in rats that experienced enhanced maternal care early in life versus control groups The reduced number of vGlut2-positive glutamatergic synapses abutting CRH-expressing cells could be a result of either a diminished number of synapses or a reduced synapse size. To distinguish between these two possibilities, we examined the density and structural identity of synapses onto CRH cells using electron microscopy. After immunolabeling for $\mathrm{CRH}$, symmetric (inhibitory) and asym- metric (excitatory) synapses onto $\mathrm{CRH}$ neurons in the parvocellular PVN were examined using stereological principles. Total synaptic density was lower in experience-augmented rats compared with control cohorts $(18.9 \pm 6.2$ vs $34.8 \pm 5.2$ synapses $/ 100 \mu \mathrm{m}$ somatic membrane; $p<$ $0.05)$ (Fig. 5). Additional analysis revealed that this reduction was attributable primarily to a drastically decreased density of asymmetric excitatory synapses (from $11.6 \pm 3.7$ to $3.4 \pm 2.2$ synapses $/ 100 \mu \mathrm{m}$ somatic membrane; $p<0.05$ ) (Fig. 5). In contrast to this $\sim 70 \%$ reduction in asymmetric synapses, the number of symmetric inhibitory synapses were not influenced by early-life experience (experience-augmented rats, $15.5 \pm 5.2$ synapses $/ 100 \mu \mathrm{m}$ somatic membrane vs undisturbed controls, $20.9 \pm 2.3$ synapses $/ 100 \mu \mathrm{m}$ somatic membrane) (Fig. 5).

\section{The frequency of mEPSC events is reduced in parvocellular-presumed CRH neurons of augmented early-life experience rats versus undisturbed controls}

The data above indicated that CRH-expressing neurons in the PVN of experienceaugmented rats were contacted by fewer asymmetric, vGlut2-positive, excitatory synapses. However, whether these structural changes influenced functional excitatory input impinging on these $\mathrm{CRH}$ neurons was unclear. Therefore, afferent inputs to presumed CRH neurons were measured using whole patch-clamp recordings in acute hypothalamic slices from experience-augmented and control P9 rats. Cells from the CRH-rich dorsal parvocellular region of the PVN (Fig. $6 E$ ) were held at $-60 \mathrm{mV}$ in the whole-cell voltage-clamp configuration, in the presence of TTX to block all action potential-driven PSCs. This enabled us to examine the frequency of mEPSCs/mIPSCs that arise from spontaneous vesicle fusion and typically reflect the number of transmitter release sites (or the probability of release) (Regehr et al., 2001). Analysis revealed that augmented early-life experience drastically reduced the frequency of mEPSCs $[17.8 \pm 2.8$ per minute $(n=17)$ compared with that in controls (44.2 \pm 9.4 per minute; $n=15) ; p<0.01$ ] (Fig. $6 A, B)$, consistent with reduced numbers of presynaptic terminals (or reduced probability of release). Whereas this reduced frequency of mPSC events is indicative of presynaptic changes, the amplitude of these currents is an indication of postsynaptic changes (e.g., receptor number, function, or both) (Regehr et al., 2001). mEPSC amplitude was modestly increased in the experience-augmented rats $(-12.4 \pm 0.7 \mathrm{pA} ; n=15)$ when compared with the control pups $(-10.5 \pm 0.6 \mathrm{pA} ; n=14 ; p<0.05)$ (Fig. $6 B$ ). In contrast to the changes in excitatory synapses, the frequency of mIPSCs did not differ between groups (control, $47.5 \pm 13.6$ per minute, $n=15$ vs experience-augmented rats, $52.8 \pm 7.4$ per minute, $n=16$ ) (Fig. $6 C, D)$, whereas the amplitude increased modestly $(-30.7 \pm 2.3 \mathrm{pA}$, $n=15$ vs $-47.8 \pm 6.8 \mathrm{pA}, n=16$ ) (Fig. $6 D$ ). Thus, the electrophysiological data supported the results obtained with quantitative biochemical methods and confocal and electron microscopy. 
Reduced excitatory input is not required for the maintenance of repressed CRH expression in hypothalamic neurons

$\mathrm{CRH}$ expression is repressed for life by augmented early-life experience (Fig. 2). The data above raised the possibility that this repression was both initiated and maintained by reduction in excitatory input. Alternatively, repression of $\mathrm{CRH}$ expression after augmented early-life experience might become autonomous, so that altered innervation of the CRH neuron was not required for the maintenance of this effect. To address this question, we examined excitatory and inhibitory synaptic input onto hypothalamic $\mathrm{CRH}-$ expressing neurons in older rats (P30P45). Examining the levels of vGlut2, we found that by P45, protein levels of vGlut2 were no longer significantly lower than those of the control rats [145.9 \pm 19.91 vs $112.8 \pm 47.86$ OD units (normalized per actin); $p>0.05]$, consistent with normalization of excitatory synapse input onto $\mathrm{CRH}$ neurons of the former. In accordance with this notion, the frequency of mEPSCs and mIPSCs of presumed CRH neurons in the PVN in experience-augmented and undisturbed control P30 rats were no longer different (frequency of mEPSC: control, $193 \pm 31$ per minute, $n=15$ vs experience-augmented rats, $293 \pm 48$ per minute, $n=$ 20; frequency of mIPSC: control, $276 \pm$ 105 per minute, $n=6$ vs experience-augmented rats, $414 \pm 83$ per minute, $n=6$; $p>0.05$ for all comparisons). Together, these data indicate that whereas diminished excitatory input, resulting from reduced numbers of excitatory synapses onto $\mathrm{CRH}$ neurons of experience-augmented rats, might be involved in initiating the molecular machinery that represses CRH gene expression in these cells, reduced excitation was not necessary to maintain the lifelong repression of the Crh gene.

Augmented early-life experience increases the levels of the NRSF, and this enhancement is persistent

If experience-induced "rewiring" of CRH-expressing neurons is not required for maintaining the repression of the Crh gene, what might the responsible molecular mechanisms for this persistent repression be? To address this question, we evaluated the role of NRSF in regulating the $\mathrm{Crh}$ gene by testing the ability of NRSF to bind to the Crh gene and by measuring the effects of augmented early-life experience on levels of NRSF in hypothalamic neurons. Using ChIP followed by quantitative PCR, we found that amount of "Crh gene" DNA amplified by PCR from chromatin immunoprecipitated with antiserum to NRSF was $39.2 \pm 4.7 \mathrm{ng}$, indicating binding of the repressor to the regulatory region of the gene (Fig. $7 A, B$ ). The amount of $\mathrm{Crh}$ gene DNA immunoprecipitated with nonimmune IgG and amplified by PCR were undetectable under the ChIP conditions we used, as was
B

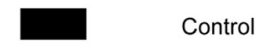

Augmented-experience

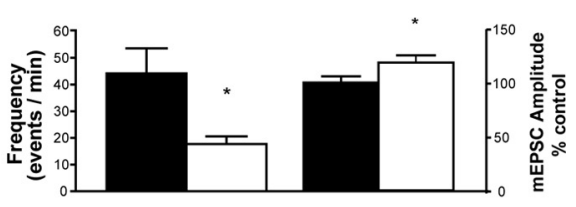

$\frac{1}{1 \mathrm{~s}} 10 \mathrm{pA}$

D

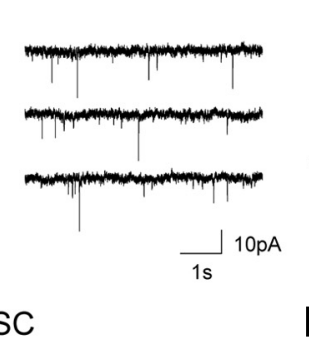

Augmented-experience
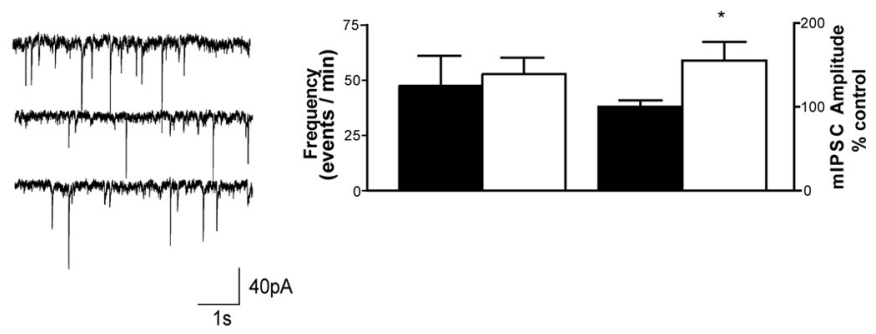

$\prod_{1 \mathrm{~s}} 40 \mathrm{pA}$
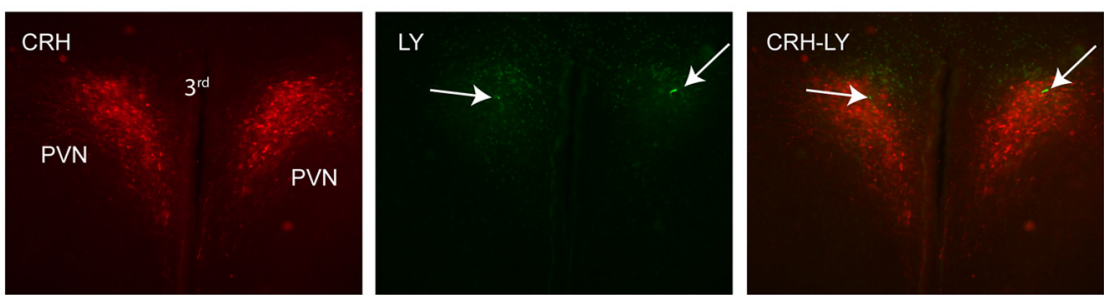

Figure 6. The frequency of mEPSC onto parvocellular CRH neurons is diminished in slices from augmented early-life experience rats. $\boldsymbol{A}$, Raw traces of recorded mEPSCs from control and augmented early-life experience $P 9$ rats are presented. mEPSCS were recorded in the presence of TTX $(1 \mu \mathrm{m})$ and bicuculline (30 $\mu \mathrm{m})$. B, Quantification representing mEPSC frequency and amplitude , accompanied by a mild increase in the amplitude of mEPSC indicative of minor postsynaptic changes. $C$, Raw traces of (the parvocellular-presumed CRH neurons. The frequency of mIPSC was not affected by the augmented early-life experience, whereas amplitude of mIPSC was increased, indicative of postsynaptic changes. $\boldsymbol{E}$, To identify the recorded neurons, they were filled with $L Y$ at the time of recording and processed for $C R H$ immunostaining. Because of leakage of cell contents and the LY in recorded neurons, only a minority were dually labeled. Therefore, all recorded neurons considered for analysis came from the CRH-rich, dorsomedial parvocellular PVN field as shown. Scale bar, $200 \mu \mathrm{m}$. Data are represented as mean \pm SEM. ${ }^{*} p<0.05$. 3rd, Third ventricle.

the amount of amplified PCR product from the anti-NRSF immunoprecipitated DNA of the intronic region of actin, a gene devoid of NRSE sites (Fig. 7A,B). Quantifying NRSF levels in punched PVN tissue by Western blot analysis showed that NRSF migrated as a single major band $(\sim 160 \mathrm{kDa}$ ). Protein levels of NRSF (normalized per actin), on $\mathrm{P}$ 9, were dramatically higher in experience-augmented compared with control rats (147.6 \pm 23.6 vs $28.0 \pm 7.5$ OD NRSF/ actin, respectively; $p<0.05$ ) (Fig. 7C,E). The experience-induced upregulation of NRSF persisted long term. NRSF levels were still strikingly higher in young-adult experience-augmented rats compared with controls $(655.5 \pm 332.9$ vs $41.6 \pm 10.8$ OD NRSF/actin; $p<0.05$ ) (Fig. $7 D, E$ ). This augmentation of NRSF expression was selective to the PVN, because no difference in NRSF levels was found in the thalamus (control, $199.8 \pm 47.1$ OD NRSF/actin; experienceaugmented rats, $195.2 \pm 46.9$ OD NRSF/actin) (Fig. 7F). These results indicate that upregulation of NRSF levels likely contributes to both initiation and persistence of the repressed CRH expression after augmented early-life experience. 
A

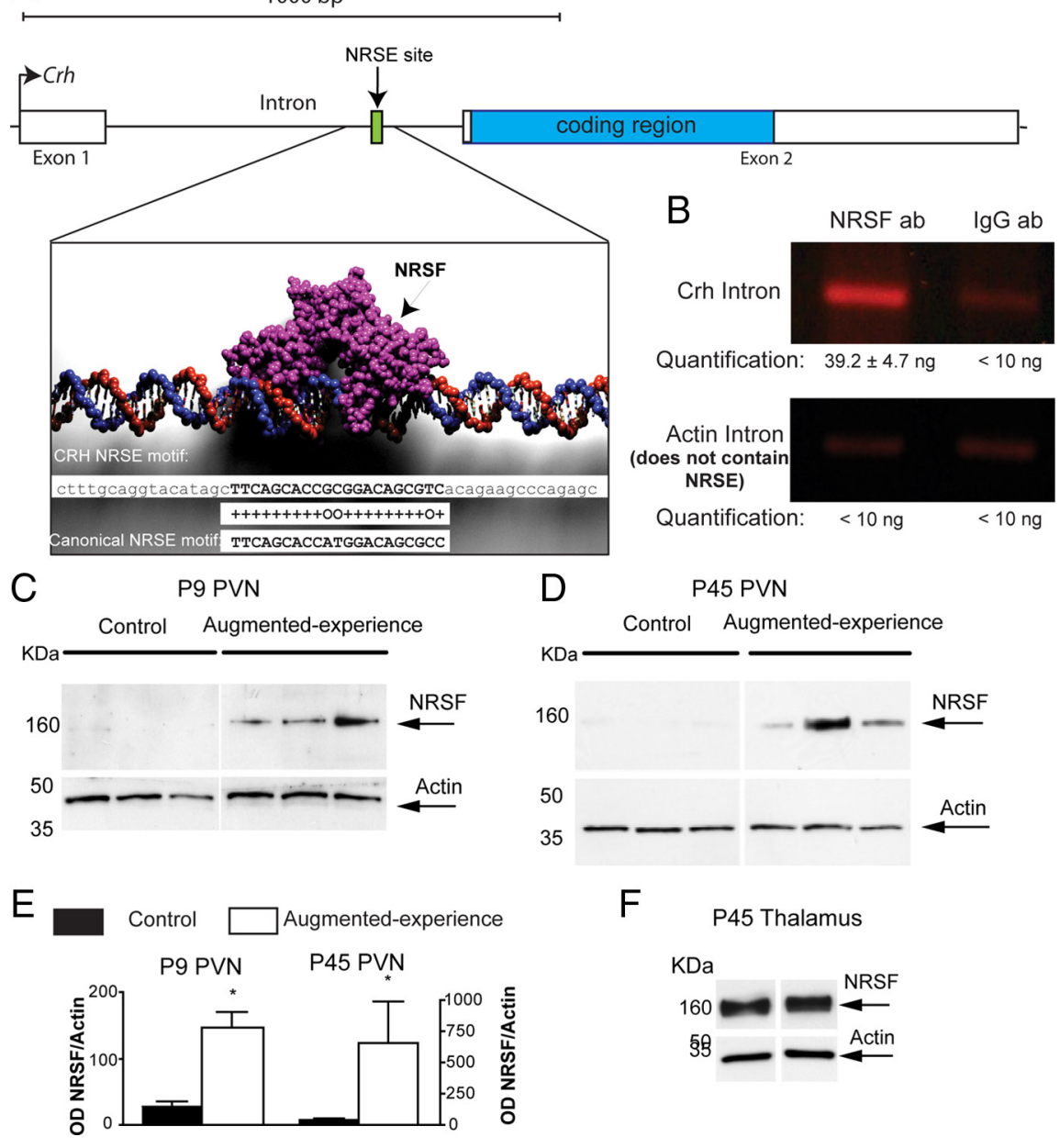

Figure 7. NRSF binds specifically to the Crh gene, and its levels are dramatically increased by augmented early-life environment. $A$, Schematic view of the chromatin of the $C r h$ gene. The regulatory region of the C $r h$ gene contains an intronic NRSE, and NRSF acts as a transcriptional repressor by binding to this element, recruiting cofactors and inducing epigenetic modification of gene expression. B, Top, Amplified Crh intron DNA immunoprecipitated with anti-NRSF, yielding $\sim 40 \mathrm{ng}$ of DNA. This is compared with undetectable DNA products immunoprecipitated with nonimmune lgG. Bottom, As an additional control for the method, the amounts of amplified Actin intron DNA (a gene devoid of an NRSE) that immunoprecipitates with anti-NRSF or with nonimmune $\lg G$ are nil. These results indicate that NRSF specifically binds to the cognate sequence (NRSE), which is located within the (rh intron. Ab, Antibody. C, $\boldsymbol{E}$, Representative Western blots and quantitative analyses of NRSF protein expression in the PVN of P9 controls and augmented-experience rats. In concurrently run samples from both groups, NRSF levels were strikingly (5-fold) increased in augmented-experience rats compared with controls. $\boldsymbol{D}, \boldsymbol{E}$, Western blots and quantitative analysis of NRSF protein expression in the PVN of $\mathrm{P} 45$ controls and augmented-experience rats. The increase in NRSF levels observed on $\mathrm{P9}$ was persistent, as evident from the 12-fold increase in NRSF levels on P45. $\boldsymbol{F}$, NRSF levels were not altered by the augmented experience in the thalamus, indicating that the effect of augmented early-life experience on NRSF expression was specific to the PVN. Data are represented as mean \pm SEM. ${ }^{*} p<0.05$.

\section{Discussion}

The studies described here demonstrate that after augmented early-life experience, the following occur:(1) expression of $\mathrm{CRH}$ mRNA and protein in hypothalamic PVN neurons is depressed, and (2) this depression is maintained to adulthood; (3) functional glutamatergic innervation of $\mathrm{CRH}$ neurons in the hypothalamus is markedly reduced, and (4) this experienceinduced reduction in excitatory innervation resolves by adulthood, indicating that the diminished excitatory input to the $\mathrm{CRH}$ neuron is not required for the maintenance of the "reprogrammed" expression levels of this gene; (5) augmented early-life experience induces a marked increase in levels of NRSF, a transcription factor negatively regulating $\mathrm{Crh}$ gene expression, and this repressor binds directly to the regulatory region of the gene; and (6) increased NRSF levels persist to adulthood. Together, these results support the idea that augmented early-life experience reduces excitatory input onto $\mathrm{CRH}$ expressing neurons. This reduced excitation is associated with, and perhaps initiates, a cascade of molecular events, including upregulation of NRSF, which may function to repress $\mathrm{CRH}$ expression. Whereas excitation to the $\mathrm{CRH}$ neuron normalizes with age, augmented NRSF levels persist, potentially contributing to maintenance of the enduring repression of $\mathrm{CRH}$ expression.

\section{Early-life experience rewires hypothalamic neurons}

Our data indicate that the input organization of neurons in the developing hypothalamus is not hardwired but, rather, may be influenced by early-life experience. Combining molecular, morphological, ultrastructural, and functional approaches, we found that the number of excitatory, vGlut2-ir boutons contacting CRH neurons was diminished in experience-augmented rats. This was associated with reduced vGlut2 levels in the PVN and reduced frequency of mEPSCs, and all these parameters remained unchanged in inhibitory synapses. The decreased frequency of mEPSCs could be interpreted either as reduced presynaptic excitatory elements or as reduced release probability (Regehr et al., 2001); however, the reduction in asymmetric synapses onto CRH neurons, observed using electron microscopy, supports the former possibility (the minor but significant changes in the amplitude of the mPSCs suggest postsynaptic changes that will need further investigation). Similarly, reduced total vGlut2 levels might be a result of reduced synapse size rather than synapse number, but the confocal and electron microscopy studies clarified that the number of excitatory synapses onto identified CRH neurons was attenuated after augmented early-life experience. Together, these data provide evidence for significant reduction in excitatory input onto CRH-expressing neurons of experience-augmented rats (i.e., a rewiring of these neurons).

$\mathrm{CRH}$ neurons in the PVN integrate excitatory and inhibitory drives from a number of sources. Both stimulatory and inhibitory afferents from limbic and cortical areas are known to coordinate CRH expression and release (Sawchenko and Swanson, 1983), yet there is little direct innervation of CRH neurons from these regions (Herman et al., 2004). Instead, axons originating in hippocampus, septum, amygdala, and prefrontal cortex contact local (peri-PVN) or remote (BnST, preoptic area) relay GABAergic or glutamatergic neurons (Tribollet and Dreifuss, 1981; Herman et al., 2004). Monosynaptic GABAergic inputs onto CRH neurons originate in regions surrounding the PVN and the BnST and 
maintain a strong inhibitory tone over CRH neurons (Roland and Sawchenko, 1993; Cullinan et al., 1996). Suppression of this tonic GABAergic inhibition enables secretion of $\mathrm{CRH}$ in response to glutamatergic activation (Cole and Sawchenko, 2002; Bartanusz et al., 2004), and functional changes in GABAergic synapses abutting $\mathrm{CRH}$ neurons have been described in response to physiological challenges (Miklos and Kovacs, 2002; Verkuyl et al., 2004; Ziegler et al., 2005). Glutamatergic inputs onto CRH cells in PVN originate from other hypothalamic nuclei and from BnST and amygdala (Aubry et al., 1996; Kiss et al., 1996; Di et al., 2003; Herman et al., 2004; Wittmann et al., 2005). Indeed, our previous work suggests that augmented early-life experience may reduce such excitatory input by activating a powerful inhibitory signal to amygdala or BnST from the thalamic paraventricular nucleus (Bhatnagar and Dallman, 1998; Fenoglio et al., 2006). The ability of glutamate and GABA to trigger direct synaptic actions in presumed $\mathrm{CRH}$ neurons (Boudaba et al., 1996, 1997) and the fact that excitation of these neurons provokes rapid transcription of the Crh gene (Cole and Sawchenko, 2002; Foradori et al., 2007), whereas elevating brain GABA levels represses CRH expression (Tran et al., 1999; Cole and Sawchenko, 2002), support the idea that the reduced balance of excitation/ inhibition found here after early-life experience leads to suppression of CRH expression.

\section{Early-life experience reprograms expression of stress-related molecules}

The consequences of early-life experience (i.e., a phenotype of reduced stress responsiveness) (Plotsky and Meaney, 1993; Avishai-Eliner et al., 2001a) and improved learning and memory (Liu et al., 2000; Fenoglio et al., 2005) is associated with lifelong increased expression of GR in hippocampus and reduced expression of CRH in PVN neurons (Plotsky and Meaney, 1993; Liu et al., 1997; Fenoglio et al., 2005; Plotsky et al., 2005). We have found previously that suppression of CRH mRNA commenced already on $\mathrm{P} 9$ and that reduction in $\mathrm{CRH}-\mathrm{CRH}$ receptor signaling sufficed to endow immature rats with this phenotype (Fenoglio et al., 2005). Therefore, we focused here on the mechanisms by which augmented early-life experience regulated CRH expression, reprogramming this expression at lower levels. As mentioned above, we found that early-life experience reduced excitation to $\mathrm{CRH}$-expressing neurons and increased expression of the transcriptional repressor NRSF. However, although the experience-induced repression of $\mathrm{CRH}$ expression persisted, the innervation of the CRH neurons normalized by adulthood. These findings suggest that reduced excitation might contribute to the initiation of the reprogramming of $\mathrm{CRH}$ expression levels but was not required for its maintenance. Rather, the cellular programs repressing expression of the Crh gene have become autonomous of the reduced excitatory input.

What might these cellular mechanisms be? The levels of the transcriptional repressor NRSF were dramatically (5- to 12-fold) elevated in PVN of experience-augmented rats, and this elevation persisted in parallel to repressed CRH expression. NRSF, originally thought to silence neuronal genes in non-neural cells, is now known to be involved in neuronal plasticity (Palm et al., 1998). NRSF binds to a 21 bp sequence (NRSE), and this sequence is found within the regulatory region (intron) of the Crh gene (Seth and Majzoub, 2001). Our data are the first to show that NRSF binds specifically to this NRSE in vivo, in the hypothalamus of the developing rat. This binding should promote recruitment of cofactors contributing to epigenetic chromatin modification (Zheng et al., 2009) and, if increased after augmented maternal care, should result in repression of transcription of the Crh gene. The involvement of epigenetic mechanisms in the programming of the hypothalamic pituitary adrenal axis by early-life maternal care has been demonstrated at the level of the promoter region of GR (Weaver et al., 2005, 2006, 2007). The enduring enhancement of hypothalamic NRSF levels, combined with the specific binding of this repressor to the Crh gene are consistent with effects of this repressor on transcription of the Crh gene throughout life.

The relationship of reduced excitation and NRSF expression is intriguing. It has been shown that neuronal activity can influence NRSF expression; for example, abnormally increased synchronized excitation (seizures) augments NRSF expression in hippocampus (Palm et al., 1998; McClelland et al., 2008). In addition, and germane to the current study, the levels of NRSF diminish rapidly during the developmental period discussed here (Palm et al., 1998). Whereas the regulation of this developmental decline of NRSF is not fully understood, it is tempting to speculate that age-dependent increase in synaptic input might be responsible for this reduction. If so, then the decreased excitatory synaptic input onto the hypothalamic $\mathrm{CRH}$ cell, provoked by augmented maternal care, should result in increased NRSF levels, as found here.

In summary, early-life experience leads to transient rewiring of hypothalamic neurons and reprogramming of Crh gene expression at suppressed levels. These result in a lifelong phenotype of reduced stress responsiveness as well as improved cognitive function. Therefore, understanding the basis of this experiencerelated plasticity is profoundly important to human health and disease and should provide the foundation of future therapeutic interventions.

\section{References}

Aubry JM, Bartanusz V, Pagliusi S, Schulz P, Kiss JZ (1996) Expression of ionotropic glutamate receptor subunit mRNAs by paraventricular corticotropin-releasing factor (CRF) neurons. Neurosci Lett 205:95-98.

Avishai-Eliner S, Eghbal-Ahmadi M, Tabachnik E, Brunson KL, Baram TZ (2001a) Down-regulation of hypothalamic corticotropin-releasing hormone messenger ribonucleic acid (mRNA) precedes early-life experience-induced changes in hippocampal glucocorticoid receptor mRNA. Endocrinology 142:89-97.

Avishai-Eliner S, Gilles EE, Eghbal-Ahmadi M, Bar-El Y, Baram TZ (2001b) Altered regulation of gene and protein expression of hypothalamicpituitary-adrenal axis components in an immature rat model of chronic stress. J Neuroendocrinol 13:799-807.

Bartanusz V, Muller D, Gaillard RC, Streit P, Vutskits L, Kiss JZ (2004) Local gamma-aminobutyric acid and glutamate circuit control of hypophyseotrophic corticotropin-releasing factor neuron activity in the paraventricular nucleus of the hypothalamus. Eur J Neurosci 19:777-782.

Bhatnagar S, Dallman M (1998) Neuroanatomical basis for facilitation of hypothalamic-pituitary-adrenal responses to a novel stressor after chronic stress. Neuroscience 84:1025-1039.

Boudaba C, Szabo K, Tasker JG (1996) Physiological mapping of local inhibitory inputs to the hypothalamic paraventricular nucleus. J Neurosci 16:7151-7160.

Boudaba C, Schrader LA, Tasker JG (1997) Physiological evidence for local excitatory synaptic circuits in the rat hypothalamus. J Neurophysiol 77:3396-3400.

Brewster AL, Bernard JA, Gall CM, Baram TZ (2005) Formation of heteromeric hyperpolarization-activated cyclic nucleotide-gated (HCN) channels in the hippocampus is regulated by developmental seizures. Neurobiol Dis 19:200-207.

Brown CP, Smotherman WP, Levine S (1977) Interaction-induced reduction in differential maternal responsiveness: an effect of cue-reduction or behavior? Dev Psychobiol 10:273-280.

Cole RL, Sawchenko PE (2002) Neurotransmitter regulation of cellular activation and neuropeptide gene expression in the paraventricular nucleus of the hypothalamus. J Neurosci 22:959-969.

Cullinan WE (2000) GABA(A) receptor subunit expression within hy- 
pophysiotropic CRH neurons: a dual hybridization histochemical study. J Comp Neurol 419:344-351.

Cullinan WE, Helmreich DL, Watson SJ (1996) Fos expression in forebrain afferents to the hypothalamic paraventricular nucleus following swim stress. J Comp Neurol 368:88-99.

Di S, Malcher-Lopes R, Halmos KC, Tasker JG (2003) Nongenomic glucocorticoid inhibition via endocannabinoid release in the hypothalamus: a fast feedback mechanism. J Neurosci 23:4850-4857.

Fenoglio KA, Brunson KL, Avishai-Eliner S, Stone BA, Kapadia BJ, Baram TZ (2005) Enduring, handling-evoked enhancement of hippocampal memory function and glucocorticoid receptor expression involves activation of the corticotropin-releasing factor type 1 receptor. Endocrinology 146:4090-4096.

Fenoglio KA, Chen Y, Baram TZ (2006) Neuroplasticity of the hypothalamicpituitary-adrenal axis early in life requires recurrent recruitment of stressregulating brain regions. J Neurosci 26:2434-2442.

Foradori CD, Lund TD, Nagahara AH, Koenig JI, Handa RJ (2007) Corticotropin-releasing hormone heterogeneous nuclear RNA (hnRNA) and immunoreactivity are induced in extrahypothalamic brain sites by kainic-acid-induced seizures and are modulated by estrogen. Brain Res 1164:44-54.

Fremeau RT, Jr, Kam K, Qureshi T, Johnson J, Copenhagen DR, StormMathisen J, Chaudhry FA, Nicoll RA, Edwards RH (2004) Vesicular glutamate transporters 1 and 2 target to functionally distinct synaptic release sites. Science 304:1815-1819.

Gao XB, van den Pol AN (2001) Melanin concentrating hormone depresses synaptic activity of glutamate and GABA neurons from rat lateral hypothalamus. J Physiol 533:237-252.

Herman JP, Mueller NK, Figueiredo H (2004) Role of GABA and glutamate circuitry in hypothalamo-pituitary-adrenocortical stress integration. Ann N Y Acad Sci 1018:35-45.

Herzog E, Bellenchi GC, Gras C, Bernard V, Ravassard P, Bedet C, Gasnier B, Giros B, El Mestikawy S (2001) The existence of a second vesicular glutamate transporter specifies subpopulations of glutamatergic neurons. J Neurosci 21:RC181(1-6).

Horvath TL (2005) The hardship of obesity: a soft-wired hypothalamus. Nat Neurosci 8:561-565.

Joëls M, Baram TZ (2009) The neuro-symphony of stress. Nat Rev Neurosci 10:459-466.

Kiss J, Gorcs TJ, Kuhn R, Knopfel T, Csaky A, Halasz B (1996) Distribution of metabotropic glutamate receptor la in the rat hypothalamus: an immunocytochemical study using monoclonal and polyclonal antibody. Acta Biol Hung 47:221-237.

Levine S (1967) Maternal and environmental influences on the adrenocortical response to stress in weanling rats. Science 156:258-260.

Liu D, Diorio J, Tannenbaum B, Caldji C, Francis D, Freedman A, Sharma S, Pearson D, Plotsky PM, Meaney MJ (1997) Maternal care, hippocampal glucocorticoid receptors, and hypothalamic-pituitary-adrenal responses to stress. Science 277:1659-1662.

Liu D, Diorio J, Day JC, Francis DD, Meaney MJ (2000) Maternal care, hippocampal synaptogenesis and cognitive development in rats. Nat Neurosci 3:799-806.

McIntire SL, Reimer RJ, Schuske K, Edwards RH, Jorgensen EM (1997) Identification and characterization of the vesicular GABA transporter. Nature 389:870-876.

Meaney MJ, Viau V, Bhatnagar S, Betito K, Iny LJ, O’Donnell D, Mitchell JB (1991) Cellular mechanisms underlying the development and expression of individual differences in the hypothalamic-pituitary-adrenal stress response. J Steroid Biochem Mol Biol 39:265-274.

Miklos IH, Kovacs KJ (2002) GABAergic innervation of corticotropinreleasing hormone $(\mathrm{CRH})$-secreting parvocellular neurons and its plasticity as demonstrated by quantitative immunoelectron microscopy. Neuroscience 113:581-592.

Mori N, Schoenherr C, Vandenbergh DJ, Anderson DJ (1992) A common silencer element in the SCG10 and type II Na + channel genes binds a factor present in nonneuronal cells but not in neuronal cells. Neuron 9:45-54.

Nelson JD, Denisenko O, Bomsztyk K (2006) Protocol for the fast chromatin immunoprecipitation (ChIP) method. Nat Protoc 1:179-185.

Palkovits M (1973) Isolated removal of hypothalamic or other brain nuclei of the rat. Brain Res 59:449-450.

Palm K, Belluardo N, Metsis M, Timmusk T (1998) Neuronal expression of zinc finger transcription factor REST/NRSF/XBR gene. J Neurosci 18:1280-1296.

Plotsky PM, Meaney MJ (1993) Early, postnatal experience alters hypothalamic corticotropin-releasing factor (CRF) mRNA, median eminence CRF content and stress-induced release in adult rats. Brain Res Mol Brain Res 18:195-200.

Plotsky PM, Thrivikraman KV, Nemeroff CB, Caldji C, Sharma S, Meaney MJ (2005) Long-term consequences of neonatal rearing on central corticotropin-releasing factor systems in adult male rat offspring. Neuropsychopharmacology 30:2192-2204.

Regehr WG, Stevens CF, Cowan WM (2001) Physiology of synaptic transmission and short-term plasticity. In: Synapses (Stevens CF, ed), pp 135175. Baltimore: Johns Hopkins UP.

Roland BL, Sawchenko PE (1993) Local origins of some GABAergic projections to the paraventricular and supraoptic nuclei of the hypothalamus in the rat. J Comp Neurol 332:123-143.

Sawchenko PE, Swanson LW (1983) The organization of forebrain afferents to the paraventricular and supraoptic nuclei of the rat. J Comp Neurol 218:121-144.

Sawchenko PE, Swanson LW (1985) Localization, colocalization, and plasticity of corticotropin-releasing factor immunoreactivity in rat brain. Fed Proc 44:221-227.

Seth KA, Majzoub JA (2001) Repressor element silencing transcription factor/neuron-restrictive silencing factor (REST/NRSF) can act as an enhancer as well as a repressor of corticotropin-releasing hormone gene transcription. J Biol Chem 276:13917-13923.

Tran V, Hatalski CG, Yan XX, Baram TZ (1999) Effects of blocking GABA degradation on corticotropin-releasing hormone gene expression in selected brain regions. Epilepsia 40:1190-1197.

Tribollet E, Dreifuss JJ (1981) Localization of neurones projecting to the hypothalamic paraventricular nucleus area of the rat: a horseradish peroxidase study. Neuroscience 6:1315-1328.

Verkuyl JM, Hemby SE, Joels M (2004) Chronic stress attenuates GABAergic inhibition and alters gene expression of parvocellular neurons in rat hypothalamus. Eur J Neurosci 20:1665-1673.

Weaver IC, Champagne FA, Brown SE, Dymov S, Sharma S, Meaney MJ, Szyf M (2005) Reversal of maternal programming of stress responses in adult offspring through methyl supplementation: altering epigenetic marking later in life. J Neurosci 25:11045-11054.

Weaver IC, Meaney MJ, Szyf M (2006) Maternal care effects on the hippocampal transcriptome and anxiety-mediated behaviors in the offspring that are reversible in adulthood. Proc Natl Acad Sci U S A 103:3480-3485.

Weaver IC, D'Alessio AC, Brown SE, Hellstrom IC, Dymov S, Sharma S, Szyf M, Meaney MJ (2007) The transcription factor nerve growth factorinducible protein a mediates epigenetic programming: altering epigenetic marks by immediate-early genes. J Neurosci 27:1756-1768.

Wittmann G, Lechan RM, Liposits Z, Fekete C (2005) Glutamatergic innervation of corticotropin-releasing hormone- and thyrotropin-releasing hormone-synthesizing neurons in the hypothalamic paraventricular nucleus of the rat. Brain Res 1039:53-62.

Zheng D, Zhao K, Mehler MF (2009) Profiling RE1/REST-mediated histone modifications in the human genome. Genome Biol 10:R9.

Ziegler DR, Cullinan WE, Herman JP (2005) Organization and regulation of paraventricular nucleus glutamate signaling systems: N-methyl-Daspartate receptors. J Comp Neurol 484:43-56. 